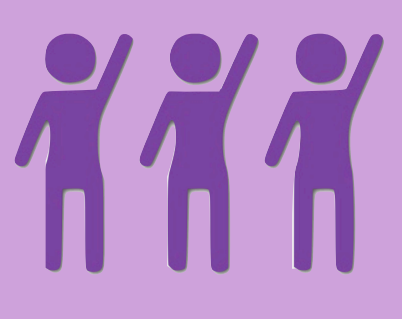

\title{
Teorias lésbicas contemporâneas e a arte como ativismo e potência de resistência e visibilidade
}

Simone BRANDÃo, Universidade Federal do Recôncavo da Bahia

O artigo busca, a partir da aproximação com diferentes teóricas do pensamento lésbico contemporâneo, discutir a importância da promoção da visibilidade lésbica, em especial de lésbicas com vidas precárias, a exemplo de mulheres negras em situação de encarceramento que se relacionam afetiva e sexualmente com mulheres. Reflete, assim, sobre a necessidade de investimento em uma produção teórica brasileira interseccional sobre lesbianidade, a partir das próprias experiências lésbicas e sugere a arte como expressão e possibilidade de militância feminista lésbica com potência para promover a visibilidade, sendo, ainda, resistência e produção de conhecimento sobre si.

PALAVRAS-Chave: Lésbicas. Arte. Ativismo. Visibilidade. 
Em tempos tão sombrios, como os que atravessa a nossa sociedade, de extremo conservadorismo e contralaicização do Estado, nos quais se instaura no país um golpe de caráter político e jurídico, estabelecendo-se um Estado de exceção, iniciativas como o Curso e a Jornada do Pensamento Lésbico Contemporâneo se fazem imperativas.

Vivemos, no Brasil, uma época na qual se reproduzem socialmente discursos machistas, sexistas, misóginos, lgbtfóbicos e racistas. Assim, falas e ações, sem o menor constrangimento, atacam violentamente, ferindo corpos e dignidades.

Todo esse contexto de trevas revela a necessidade de não silenciarmos e prosseguirmos contribuindo na construção de um pensamento crítico e emancipatório sobre essas questões - o que é urgente.

É nesse sentido, que se faz imprescindível visibilizar a força da lesbianidade, entendida aqui como um posicionamento político, mais do que apenas uma identidade ou uma orientação sexual. Trata-se de uma possibilidade de rasura do sistema heteronormativo e da heterossexualidade compulsória, como afirmam Curiel (2017) e Rich (2010).

Dessa forma, ao ser convidada para discutir sobre teorias lésbicas contemporâneas, optei por trazer uma reflexão sobre a aplicabilidade dessas teorias, reconhecendo que o momento nos exige não só o domínio das mesmas, mas especialmente o exercício de uma prática que se sustenta nessas teorias. Com isso, é necessário construir imediatamente uma práxis que remeta à transformação material da realidade.

Temos discutido, em algumas comunicações que realizamos sobre lesbianidade, a invisibilidade lésbica e a necessidade de promover uma visibilidade como forma de potencializar nossas existências. Em especial, quando nos referimos a lésbicas que não possuem qualquer tipo de privilégio social, quando são vidas precárias, como as de mulheres negras lésbicas em situação de encarceramento - as quais são o foco de dedicação, por meio de atividades de pesquisa e extensão, do grupo LES - Laboratório de Estudos e Pesquisas em Lesbianidades, Gênero, Raça e Sexualidades da Universidade Federal do Recôncavo da Bahia (UFRB), coordenado por mim.

Quando refletimos sobre a situação da lésbica negra em situação de encarceramento, podemos recorrer ao termo outsider, categoria 
desenvolvida por Norbert Elias (2000) no livro "Os estabelecidos e os outsiders", a partir de uma análise das relações de poder presentes em uma pequena cidade do interior da Inglaterra, sinalizando a cisão identitária da sociedade local, apartada em dois grupos distintos: os estabelecidos e os outsiders.

Nesse estudo, Elias (2000) define os estabelecidos como um dos grupos da comunidade estudada no qual as pessoas se reconhecem e se autopercebem como um grupo com valores morais superiores, sendo, portanto, empoderadas. Já os outsiders, embora pertençam à mesma comunidade, são aqueles considerados fora dela e avaliados como moralmente inferiores, sendo estigmatizados por não partilharem as tradições e a coesão daquele grupo, ou seja, a "virtude humana superior".

Tem-se, nessas relações, um desequilíbrio de poder necessário para garantir a hierarquia entre os grupos. Assim, assegurar esse desequilíbrio e manter determinado grupo no status subalternizado de outsider neutraliza a possibilidade de insurgência deste, bem como a sua mobilidade na escala de poder, ao manter sua depreciação e rotulação como humanamente inferior.

Depreende-se, portanto, que a identidade é relacional, pois se constrói na relação com o outro ao qual se atribui uma diferença constitutiva, reforçando determinada identidade enquanto se nega e se exclui a outra identidade.

Ao recorrermos à categoria outsider para nos referir às lésbicas negras em situação de encarceramento, compreendemos que as diferenciações entre estabelecidos - ou os que estão dentro - e outsiders - os que estão fora - não são apenas oposições binárias, incapazes de dar conta da multiplicidade e fluidez das identidades. As distinções, na realidade, representam sistemas culturais de classificação que objetivam o estabelecimento da ordem e do controle social, demarcando diferenças entre as identidades e criando fronteiras de inclusão e exclusão

Assim, a diferença é tomada de forma negativa, através da exclusão, da marginalização e da invisibilidade daquelas pessoas que são consideradas outsiders - a exemplo das lésbicas negras em situação de encarceramento. Entretanto, essa distinção também pode ser ressignificada se tomada como diversidade e dissidência de sexualidades, gêneros e raças com potência para desestabilizar a ordem heteronormativa, sexista e racista, presente na sociedade como um todo, mas especialmente nas instituições prisionais. 
Uma primeira ação para esse processo é a reversão da invisibilidade da lesbianidade, que se processa desde a construção discursiva da existência lésbica - por exemplo, a partir da escassa produção acadêmica sobre a temática. Durante um longo período, a lesbianidade foi tratada como um apêndice da homossexualidade gay, um quase sinônimo. Isso gerou um apagamento da existência lésbica na academia. Esse fator contribuiu especialmente no processo de invisibilização da lesbianidade e também na publicação de trabalhos que tratam dessa experiência de forma enviesada, na medida em que falam a partir de um olhar masculino, presente na maioria das produções sobre homossexualidades, que não captura as especificidades do universo lésbico.

Somente a partir da década de 1970, com o surgimento de organizações de lésbicas, inicia-se o processo afirmativo da identidade lésbica, o que contribui para o aumento de trabalhos acadêmicos no campo da lesbianidade e também para essa construção identitária.

Não é nosso objetivo essencializar as identidades nem afirmar nenhuma supremacia da produção endógena lésbica, ou mesmo deixar de considerar a pluralidade de experiências dos grupos identitários. No entanto, é importante situar a necessidade de tratar a lesbianidade a partir de um olhar distinto daquele que predomina nos estudos sobre as homossexualidades, de forma geral, nos quais se reproduzem as especificidades do universo gay sem dar visibilidade às peculiaridades do mundo lésbico.

Reivindico,, com isso, um olhar não impregnado de valores e cultura masculinos e colonizados. Em outras palavras, é fundamental que as produções sobre lesbianidade sejam pensadas não mais a partir de um discurso que constrói e significa o universo masculino, mas tendo um olhar menos impregnado da perspectiva gay-masculina-patriarcal que invisibiliza nuances específicas da lesbianidade, e por que não dizer, as próprias lésbicas, dentro do universo LGBTT.

Nesse sentido, a construção de um conhecimento para e pelas lésbicas negras e o estabelecimento de uma prática institucional potencializadora, que proporcione visibilidade a essas sujeitas, são estratégias fundamentais para enfrentar a invisibilidade perversa que, decorrente do racismo e da lesbofobia, impede a liberdade no desenvolvimento das sexualidades e subjetividades lésbicas e negras, 
bem como é obstáculo para a construção do respeito à lesbianidade e para a efetivação de direitos correlatos.

Com isso, reforço a necessidade de reconhecer a agência das lésbicas e de outras sujeitas com sexualidades não normativas, bem como de outras existências precárias, como as lésbicas negras em situação de encarceramento, para transgredir o jugo disciplinador imposto.

Acreditamos, assim, que essa capacidade de agência pode ser potencializada com o suporte das teorias lésbicas contemporâneas. O curso Pensamento Lésbico Contemporâneo teve o importante trabalho de sistematizar essa produção teórica lésbica, seja a partir de uma organização geopolítica ou identitária. Apesar de haver perspectivas teóricas distintas, existem, nessas teorias, alguns posicionamentos intersectados e complementares, a exemplo da ideia de potencialização da lesbianidade como posicionamento político e militante de resistência às opressões normativas ou mesmo a promoção da visibilidade lésbica.

Bourcier (2015), por exemplo, a partir da perspectiva teórica queer, compreende que existe, na cultura lésbica, um silêncio cultural que acaba por manter as nossas experiências apenas para nós mesmas. Porém, é necessário que nossas existências sejam visibilizadas e que as histórias sejam disseminadas.

Saunders (2017), por sua vez, feminista lésbica negra, principalmente partindo de sua experiência no Brasil como professora visitante, identificou que há uma visibilidade lésbica das identidades sapatões, mas que ainda não há uma comunidade lésbica de fato constituída fora da academia ou dos grupos de militância.

Rich (2010) aborda essa invisibilidade histórica, que sinalizamos seja na teoria ou na existência lésbica, especialmente dentro dos movimentos feministas - apagamento histórico que é reforçado por Swain (1999).

Ao recorrermos a Lorde (1984), feminista lésbica negra, vemos, em seus textos escolhidos, que, contra essa invisibilidade, que faz as mulheres negras mais vulneráveis, é preciso a quebra do silêncio, a aposta no poder da linguagem, ou ainda a transformação do silêncio em linguagem e em ação, compartilhando e difundindo palavras através de um processo de vida criativo. 
Clarke (1988), pioneira do feminismo lésbico negro, também reivindica nossa visibilidade ante a cultura dominante que mantém as lésbicas invisíveis e sem poder, em especial as mulheres negras. Assim como Rich (2010) ou Wittig (2006), a autora compreende a existência lésbica como um posicionamento político, ao tempo em que reconhece o feminismo lésbico como possibilidade de transtornar e transformar o sistema de opressão das mulheres, que é a heterossexualidade compulsória:

É uma de minhas esperanças como lesbiana-feminista que mais mulheres agora e no futuro, devido a nossa visibilidade, trabalho e energia, ponham mais valor nas suas relações com mulheres e elijam abertamente ao lesbianismo - como uma política, como um modo de vida, como uma filosofia e como um plano vital (CLARKE, 1988, p. 6).

Percebemos, ainda, que é reafirmado, entre as diferentes perspectivas teóricas, o entendimento comum de que a existência lésbica, em culturas sexistas, capitalistas, misóginas, racistas e LGBTfóbicas, é um ato de resistência, sendo mesmo uma forma de descolonizar o corpo.

Por exemplo, Dorotea Goméz Grijalva (2012), feminista lésbica, possui uma perspectiva interseccional e compreende o corpo como um território político, um instrumento histórico de descolonização patriarcal que é dotado de memória e conhecimento. Nesse sentido, Grijalva (2012) utiliza-se da experiência do corpo como possibilidade de visibilidade e resistência lésbica e narra sua experiência, usando a escrita dessa vivência como potência.

A partir dessas leituras, percebemos o quanto é necessário estimularmos e investirmos na produção teórica brasileira interseccional a respeito da existência lésbica e de sua potência, como sinalizado por Saunders (2017), ao abordar a importância da construção de uma teoria negra brasileira.

É necessário, portanto, construir uma teoria lésbica brasileira a partir das experiências que vivenciamos através não só das nossas pesquisas e atividades de extensão produzidas nas universidades, mas visibilizando as experiências de mulheres que estão fora da academia e do ativismo, a exemplo das mulheres negras lésbicas em situação de encarceramento, de forma a possibilitar sua participação nessa construção, garantindo que falem sobre as suas existências, recuperando, assim, a prática utilizada pelo feminismo negro de se 
construir a partir das experiências cotidianas de mulheres negras que não eram contempladas nas produções de outros feminismos brancos.

Dessa forma, é importante se pensar na cultura, na promoção de ações nesse campo, na utilização da arte e da cultura como ferramentas possíveis de construção dessa teoria lésbica brasileira descolonizada, embasada nas nossas existências e experiências múltiplas.

Um exemplo dessa perspectiva centrada na arte e na cultura é o trabalho baseado na resistência cultural desenvolvido por Saunders (2017) com artistas lésbicas de hip hop em Cuba. Para a autora, ignorar essa esfera cultural é limitar as ferramentas que a sociedade pode utilizar em sua participação democrática.

Nesse sentido, consideramos necessário estimular o uso de tais ferramentas, servir-se da cultura para se expressar, produzir visibilidade, utilizar a arte na militância feminista lésbica. Pensar, por exemplo, nas escrevivências, metodologia utilizada pela escritora brasileira Conceição Evaristo (2011), que consiste na potência de escrever sobre suas próprias vivências ou sobre sua sobrevivência. Isso já se fazia presente na obra de Carolina Maria de Jesus (1960), em especial no livro "Quarto de despejo", o que mostra como é possível que a escrita se torne uma potente ferramenta de resistência e de rasura do sistema.

Experiências como essas vão ao encontro da possibilidade de construirmos uma teoria própria, descolonizada, como proposto por Saunders (2017), e reforçado em Bourcier (2015). Daí a importância de fortalecer a formação política e a ampliação dessa comunidade, especialmente por aquelas que estão nas margens, que estão fora das universidades e dos movimentos de ativismos.

Por fim, gostaríamos de trazer a nossa experiência no LES Laboratório de Estudos e Pesquisas em Lesbianidades, Gênero, Raça e Sexualidades da Universidade Federal do Recôncavo da Bahia (UFRB), na qual utilizamos ferramentas culturais no processo de promoção da visibilidade de existências lésbicas precárias, como aquelas protagonizadas por mulheres negras lésbicas em situação de encarceramento do Conjunto Penal de Feira de Santana, Bahia, local onde realizamos nosso projeto de extensão "Direitos sexuais de mulheres negras lésbicas em situação de encarceramento", desde 2011.

Nesse projeto, trabalhamos inicialmente com mulheres em situação de encarceramento e, posteriormente, com funcionários, através de oficinas formativas sobre gênero, raça e sexualidade. Em um segundo 
momento, promovemos oficinas no campo das artes visuais, com vídeo e fotografia. Procuramos, com isso, empregar a arte como militância feminista lésbica, de forma a extrapolar a universidade e alcançar, através de nossas atividades de extensão, esse contingente de lésbicas que estão à margem.

Desse modo, realizamos uma oficina de vídeo com o grupo de mulheres que se relacionam afetiva e sexualmente com outras mulheres na prisão, na qual produziram, como resultado final, um filme documentário. Da elaboração do roteiro à operação dos equipamentos de filmagem e som, passando pela construção das falas das personagens, tudo foi feito pelas próprias sujeitas encarceradas. Posteriormente, ainda no campo das artes visuais, realizamos uma oficina de fotografia e, como produto, as próprias sujeitas desvelaram suas existências lésbicas negras na prisão.

Podemos concluir, a partir dessa experiência, que a arte se mostra como forte possibilidade de expressão para as lésbicas e como potência de resistência, além de se configurar como oportunidade de construção de uma prática docente e discente militante, na medida em que o LES vem agregando um grupo de pesquisadoras e estudantes lésbicas e bissexuais.

Reforçamos, portanto, a importância da utilização das tecnologias, da arte e da cultura, de uma forma geral, como ativismo e possibilidade de as existências lésbicas se expressarem, terem visibilidade, serem resistência e produzirem conhecimento sobre si objetivos das teorias lésbicas contemporâneas.

\section{Referências Bibliográficas}

COSTA, Ana Alice et al. Uma conversa franca com MH/Sam Bourcier sobre correntes feministas e queer na contemporaneidade. Feminismos, Salvador, vol. 3, n. 2/3, p. 48-59, maio - dez/2015.

CLARKE, Cheryl. El lesbianismo, un acto de resistencia. In: Moraga, Cherrie; Castillo, Ana (Org.). Esta puente, mi espalda. Voces de Mujeres tercermundistas en los Estados Unidos. San Francisco. California. 1988, p. 99-107. Tradução de Ana Castillo e Norma Alarcó n. 
ELIAS, Norbert; SCOTSON, John L. Os estabelecidos e os outsiders: sociologia das relações de poder a partir de uma pequena comunidade. Rio de Janeiro: Jorge Zahar, 2000, 228 p. Tradução de Vera Ribeiro.

EVARISTO, Conceição. Insubmissas lágrimas de mulheres. Belo Horizonte: Nandyala, 2011.

GRIJALVA, Dorotéa G. Mi cuerpo es un territorio político. In: VOCES Descolonizadoras. Cuaderno 1. [S.l.]: Brecha Lésbica, p. 04-27, 2012.

JESUS, Carolina Maria de. Quarto de despejo - diário de uma favelada. São Paulo: Francisco Alves, 1960, 173 p.

LORDE, Audre. Textos escolhidos de Audre Lorde. [S.l.]: Heretica Edições Lesbofeministas Independentes, [200?], 18 p. Disponível em: h t t p s : / / w e.ris e u p.n e t/a s s e t s/171382/ AUDRE\%20LORDE\%20COLETANEA-bklt.pdf. Acesso em: 03 mar. 2018.

RICH, Adrienne. Heterossexualidade compulsória e existência lésbica. Bagoas, Natal, vol. 04, n. 05, p. 17-44, 2010.

SAUNDERS, Tanya L. Epistemologia negra sapatão como vetor de uma práxis humana libertária. Revista Periódicus, Salvador, v. 1, n. 7. Salvador, p. 102-116, 2017.

SWAIN, Tania Navarro. Feminismo e lesbianismo: a identidade em questão. Cadernos Pagu, Campinas, n. 12, p.109-120, 1999.

WITtig, Monique. El pensamiento heterosexual e otros ensayos. Madrid: Egales, 2006. 117 p. Tradução de Javier Sáez e Paco Vidarte. 


\section{Théories lesbiennes contemporaines et art comme activisme et puissance de résistance et visibilité}

RÉSUMÉ: A partir de différentes approches théoriques de la pensée lesbienne contemporaine, cet article vise à discuter l'importance de promouvoir la visibilité lesbienne, en particulier, la visibilité de lesbiennes dont les vies sont précires, comme par exemple, de femmes noires en situation d'emprisonnement se relationnant affectivement et sexuellement avec des femmes. A partir de la théorie lesbienne, il réfléchit, aussi, sur la necessité de s'investir dans une production théorique lesbienne brésilienne et une approche intersectionnelle du lesbianisme, qui part des expériences de vie lesbiennes et suggère que l'art peut être une forme d'expression et de possibilité de militance féministe lesbienne en tant que puissance de promouvoir la visibilité, la résistence et la production de connaissance de soi.

KEYWORDS: Lesbienne. Art. Activisme. Visibilité.

\section{Simone BRANDÃO}

Possui graduação em Serviço Social pela Universidade Federal Fluminense (1995), mestrado em Estudos Populacionais e Pesquisas Sociais pela Fundação Instituto Brasileiro de Geografia e Estatística (2005) e Doutorado em Cultura e Sociedade pelo Programa Multidisciplinar de Pós Graduação em Cultura e Sociedade da Universidade Federal da Bahia. Atualmente é professora Adjunta do

Curso de Serviço Social da Universidade Federal do Recôncavo da Bahia onde coordena o LES - Laboratório de Estudos e Pesquisas em Lesbianidades, Gênero, Raça e Sexualidades. Tem experiência na área de Serviço Social, direitos humanos, sexualidades, lesbianidades e gênero. 